\title{
THE EFFECTS OF RING ANNULOPLASTY ON MITRAL LEAFLET GEOMETRY DURING ACUTE LEFT VENTRICULAR ISCHEMIA
}

\author{
David T. M. Lai, FRACS ${ }^{a}$ \\ Tomasz A. Timek, $\mathrm{MD}^{\mathrm{a}}$ \\ Paul Dagum, MD, $\mathrm{PhD}^{\mathrm{a}}$ \\ G. Randall Green, $\mathrm{MD}^{\mathrm{a}}$ \\ Julie R. Glasson, MD \\ George T. Daughters, MS ${ }^{\mathrm{a}, \mathrm{b}}$ \\ David Liang, MD, $\mathrm{PhD}^{\mathrm{c}}$ \\ Neil B. Ingels, Jr, $\mathrm{PhD}^{\mathrm{a}, \mathrm{b}}$ \\ D. Craig Miller, $\mathrm{MD}^{\mathrm{a}}$
}

Background: The perturbed mitral leaflet geometry that leads to acute ischemic mitral regurgitation during acute left ventricular ischemia has not been quantified, nor is it known whether annuloplasty rings affect these detrimental changes in leaflet geometry.

Methods: Radiopaque markers were implanted on both mitral leaflets and around the anulus in 3 groups of sheep: one group without rings served as the control group $(n=7)$; the others underwent Duran $(n=6$; Medtronic Heart Valve Division, Minneapolis, Minn) or Carpentier-Edwards Physio (n = 5; Baxter Cardiovascular Division, Santa Ana, Calif) ring annuloplasty. After recovery, 3-dimensional marker coordinates were obtained by means of biplane videofluoroscopy before and during acute posterolateral left ventricular ischemia. Leaflet geometry was defined by measuring distances between annular and leaflet markers and perpendicular distances to the leaflet markers from a best-fit annular plane.

Results: In all control animals, left ventricular ischemia was associated with acute ischemic mitral regurgitation and apical displacement (away from the annular plane) of the posterior leaflet edge and base markers by $0.6 \pm 0.4$ $\mathrm{mm}(P=.01)$ and $0.7 \pm 0.2 \mathrm{~mm}(P<.001)$, respectively. The distance between the posterior leaflet markers and the mid-posterior anulus did not change significantly during ischemia. The anterior leaflet edge marker extended $1.0 \pm 0.5 \mathrm{~mm}(P=.01)$ away from the mid-anterior anulus during ischemia, but compared with its nonischemic position, the anterior leaflet was not displaced apically away from the annular plane. In all animals in the Duran and Physio groups, leaflet geometry was unchanged during ischemia, and acute ischemic mitral regurgitation was not detected.

Conclusion: Acute ischemic mitral regurgitation was associated with restricted motion of the posterior leaflet and extension of the anterior leaflet. Annuloplasty rings prevented these geometric perturbations of the mitral leaflets during acute left ventricular ischemia and preserved valvular competence. (J Thorac Cardiovasc Surg 2000;120:966-75)
From the Department of Cardiovascular and Thoracic Surgery and Division of Cardiovascular Medicine, ${ }^{c}$ Stanford University School of Medicine, Stanford, Calif, and the Laboratory of Cardiovascular Physiology and Biophysics, ${ }^{\mathrm{b}}$ Research Institute of the Palo Alto Medical Foundation, Palo Alto, Calif.

This work was supported by grants HL-29589 and HL-48837 from the National Heart, Lung, and Blood Institute. Green and Dagum were supported by National Heart, Lung, and Blood Institute Individual Research Service Awards HL-09569 and HL-10000; Green, Dagum, Lai, and Glasson are Carl and Leah McConnell Cardiovascular Surgical Research Fellows. Glasson is also a Katharine McCormick Scholar. Glasson and Timek are recipients of Thoracic Surgery Education and Research Foundation Fellowship Awards.
Read at the Eightieth Annual Meeting of The American Association for Thoracic Surgery, Toronto, Ontario, Canada, April 30-May 3, 2000.

Received for publication May 4, 2000; revisions requested June 6, 2000; revisions received July 6, 2000; accepted for publication July 14, 2000.

Address for reprints: D. Craig Miller, MD, Department of Cardiovascular and Thoracic Surgery, Falk Cardiovascular Research Center, Stanford University School of Medicine, Stanford, CA 94305-5247 (E-mail: dcm@stanford.edu).

Copyright (C) 2000 by The American Association for Thoracic Surgery

$0022-5223 / 2000 \$ 12.00+0 \quad \mathbf{1 2 / 6 / 1 1 0 1 8 6}$

doi:10.1067/mtc. 2000.110186 
$T_{\text {to }}^{\text {he }}$ he perturbations of mitral leaflet geometry that lead to acute ischemic mitral regurgitation (MR) during acute posterolateral left ventricular (LV) ischemia have not been adequately quantified. Echocardiographic assessment of altered leaflet dynamic motion in clini$\mathrm{cal}^{1-5}$ and experimental studies ${ }^{6-11}$ has generated discordance with respect to the direction of leaflet displacement and the portion of the leaflets affected by acute LV ischemia. This lack of consensus stems from differences in experimental design (regional ${ }^{12}$ as opposed to global $^{9}$ and acute $^{6}$ as opposed to chronic ischemia ${ }^{13}$ ), mixed clinical patient cohorts combining degenerative and ischemic etiologies, ${ }^{1}$ and quality of echocardiography. Echocardiography cannot continuously track the motion of a chosen discrete point on the mitral leaflet and hence cannot measure with accuracy the magnitude of leaflet displacements during acute ischemic MR, but echocardiography does provide excellent qualitative description of the entire leaflet shape. For these reasons, echocardiographic studies have ascribed incomplete mitral leaflet closure during LV ischemia to a range of leaflet perturbations that include restriction of one or both leaflets, ${ }^{1,2}$ and, conversely, prolapse of one or both leaflets. ${ }^{3,6}$ Thus, it is difficult to gain insight into the mechanistic basis of acute ischemic MR when there is no agreement as to the fundamental shape changes that occur in the mitral leaflets during acute ischemic MR.

The relative dearth of knowledge concerning leaflet perturbations during acute ischemic MR also extends to the clinical realm, where debate continues on how best to repair these morphologically normal valves. ${ }^{14-16}$ Annuloplasty rings have been shown to be more therapeutically efficacious than suture annuloplasty in correcting ischemic $\mathrm{MR},{ }^{17-20}$ and annuloplasty rings have conferred survival benefit in selected patients with ischemic MR. ${ }^{20}$ However, the purported efficacy of annuloplasty rings in correcting ischemic MR may be confounded by the effects of myocardial revascularization and the inclusion of mixed clinical patient cohorts with nonischemic etiologies of MR. Additionally, the results of ring annuloplasty have not been uniformly predictable or consistent, ${ }^{21-23}$ and it is not clear why annuloplasty rings sometimes fail to work. Furthermore, it is not known whether mitral annuloplasty rings can prevent perturbations of leaflet shape during acute LV ischemia and thereby eliminate or minimize acute ischemic MR.

For the mechanistic basis of acute ischemic MR to be understood, it is imperative that the relationships between mitral leaflet shape and competent mitral valve closure be defined precisely. To quantify perturbations of mitral leaflet shape during acute ischemic
MR, we reanalyzed the dynamic motion of discrete radiopaque leaflet markers (with respect to the annular plane) in a control group of sheep before and during ischemia, ${ }^{24}$ as well as the impact of annuloplasty rings in preventing perturbations of mitral leaflet shape during acute LV ischemia. ${ }^{25}$

\section{Methods}

Surgical preparation. Three groups of adult castrated male sheep were studied $(n=18)$. The control group without annuloplasty rings comprised 7 sheep. The two ring groups comprised 11 sheep that were randomly assigned to undergo either Duran (Medtronic Heart Valve Division, Minneapolis, Minn) flexible ring annuloplasty $(n=6)$ or CarpentierEdwards Physio (Baxter Cardiovascular Division, Santa Ana, Calif) ring annuloplasty $(n=5)$. Radiopaque markers were surgically implanted (details previously reported ${ }^{26}$ ). Six subepicardial and 2 septal tantalum markers (inner diameter $0.8 \mathrm{~mm}$, outer diameter $1.3 \mathrm{~mm}$, length $1.5-3.0 \mathrm{~mm}$ ) were inserted along 4 equally spaced LV longitudinal meridians. On cardiopulmonary bypass through a left atriotomy, 8 miniature tantalum radiopaque markers were sutured to delineate the mitral anulus (1 near each commissure and 3 along the anterior and posterior areas of the anulus, Fig 1). Additional miniature gold markers were sutured along the middle of the anterior leaflet (4 markers numbered 9 to 12) and posterior leaflet ( 2 markers numbered 13 to 14 ) with the edge markers placed on the ventricular surface and the others on the atrial surface (Fig 1). One marker was placed at the LV apex. The annuloplasty rings were sized by estimating the area of the anterior mitral leaflet and the intertrigonal distances. The rings were not undersized: the animals in the Duran group received five 31-mm rings and one 29-mm ring, and all animals in the Physio group received a $28-\mathrm{mm}$ ring.

Experimental protocol. After an $8 \pm 2$ (mean $\pm 1 \mathrm{SD}$ ) day recovery period, each animal was taken to the experimental cardiac catheterization laboratory, premedicated with ketamine, intubated, and its lungs were mechanically ventilated (veterinary anesthesia ventilator 2000; Hallowell EMC, Pittsfield, Mass) with $100 \%$ oxygen. Ketamine (1-4 mg $\cdot \mathrm{kg}^{-1}$ $\cdot \mathrm{h}^{-1}$ intravenous [IV] infusion) and diazepam ( $5 \mathrm{mg}$ IV bolus as needed) were administered as necessary to maintain the animal in a conscious, sedated state. A micromanometertipped catheter (Millar MPC-500; Millar Instruments, Inc, Houston, Tex), previously zeroed in a $37^{\circ} \mathrm{C}$ water bath, was placed in the descending thoracic aorta to measure aortic pressure. The heart rate was slowed with IV UL-FS49 to 100 beats/min as required (a highly specific negative chronotropic agent that does not alter the QT interval, inotropic state, or blood pressure; Boehringer-Ingelheim, Ridgefield, Conn). Esmolol (20-40 $\mu \mathrm{g} \cdot \mathrm{kg}^{-1} \cdot \mathrm{min}^{-1}$ IV infusion) and atropine $\left(0.01 \mathrm{mg} \cdot \mathrm{kg}^{-1} \cdot \mathrm{IV}\right)$ were administered to reduce reflex sympathetic and parasympathetic responses, respectively.

With the animal placed in the right lateral decubitus position, simultaneous biplane videofluoroscopic and hemodynamic data were acquired under steady-state conditions and 


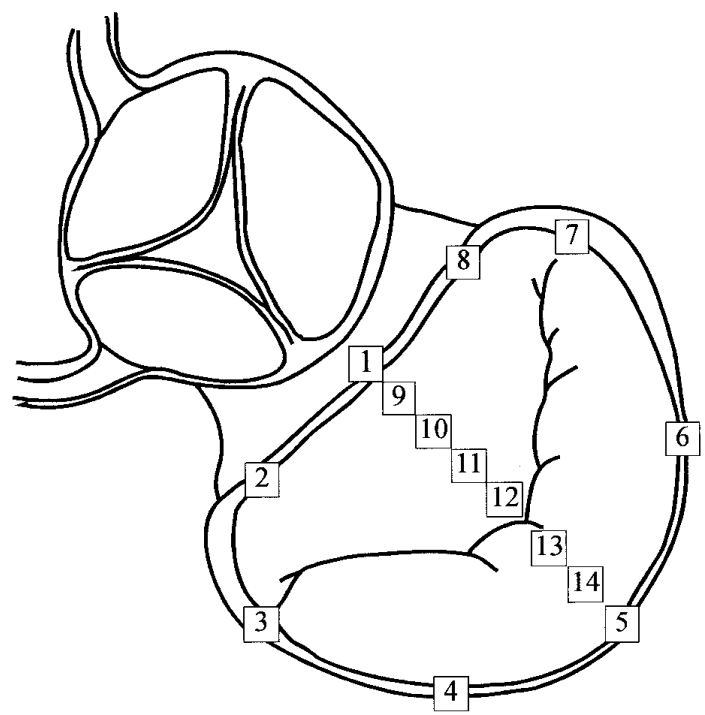

Fig 1. Miniature marker array used. Markers were sutured to the mid-anterior anulus (1), left fibrous trigone (2), anterior commissure (3), left posterior anulus (4), mid-posterior anulus (5), right posterior anulus (6), posterior commissure (7), and right fibrous trigone (8). Markers were also sutured to the midline of the anterior mitral leaflet (markers 9, 10, 11, and 12 to the free edge) and the posterior leaflet (markers 13 to the free edge and 14).

over a range of LV filling volumes with abrupt preload reduction by means of vena caval occluders. Data were obtained before and during ischemia. Animals were studied in normal sinus rhythm after autonomic blockade and with ventilation arrested at end-expiration during data acquisition runs to minimize the effects of respiration. Acute posterolateral LV ischemia was created as previously reported ${ }^{24}$ by balloon occlusion of the left circumflex coronary artery distal to the first obtuse marginal artery. Before occlusion, a loading dose of lidocaine $(1 \mathrm{mg} / \mathrm{kg}$ IV) was administered followed by a continuous infusion ( $1 \mathrm{mg} / \mathrm{min})$. An $8 \mathrm{~F}$ Powerguide coronary guiding catheter (Advanced Cardiovascular Systems, Inc, Temecula, Calif) was advanced into the left main coronary artery over a 0.014-inch HI-TORQUE floppy guide wire (Advanced Cardiovascular Systems) through an $11 \mathrm{~F}$ left carotid artery introducer. A conventional $3.5-\mathrm{mm}$ nonperfusion balloon dilation catheter was advanced over the guiding catheter and positioned proximal to the second obtuse marginal branch of the left circumflex artery. The balloon was inflated to 8 to 10 atmospheres, and coronary angiography confirmed complete occlusion of the circumflex artery. After 2 to 3 minutes of ischemia, data were acquired and the presence or absence of acute ischemic MR was ascertained by transthoracic color Doppler echocardiography. MR was graded as none, mild to moderate, or moderate to severe.

All animals received humane care in compliance with the "Principles of Laboratory Animal Care" formulated by the National Society for Medical Research and the "Guide for the Care and Use of Laboratory Animals" prepared by the National Academy of Sciences and published by the National Institutes of Health (DHEW [NIH] Publication 85-23, revised 1985). This study was approved by the Stanford Medical Center Laboratory Research Animal Review Committee and conducted according to Stanford University policy.

Data acquisition and reduction. A Philips Optimus 2000 biplane Lateral ARC 2/Poly DIAGNOST C2 system (Philips Medical Systems, North America Company, Irvine, Calif) was used to collect videofluoroscopic marker data at $60 \mathrm{~Hz}$ and 9-inch mode of image magnification. Two-dimensional (2-D) images from each of the two x-ray views $\left(45^{\circ}\right.$ right anterior oblique and $45^{\circ}$ left anterior oblique) were digitized and merged to yield 3-D coordinates for each radiopaque marker every $16.7 \mathrm{~ms}$ by means of custom-designed software. ${ }^{27}$ The analog LV pressure and electrocardiographic voltage signals were digitized and recorded in real time on the video images during data acquisition.

Data analysis. Data from 2 consecutive steady-state beats during control and acute ischemic conditions were averaged and analyzed. For each cardiac cycle, end-systole was defined as the videofluoroscopic frame immediately preceding the peak negative $\mathrm{LV}$ rate of pressure change $\left(-\mathrm{dP} / \mathrm{dt}_{\max }\right)$, and end-diastole was defined as the videofluoroscopic frame containing the peak of the $\mathrm{R}$ wave on the electrocardiogram.

$L V$ volume. Instantaneous $L V$ volume was estimated every $16.7 \mathrm{~ms}$ from the epicardial LV markers by a space-filling multiple tetrahedral volume method, as previously published. ${ }^{28}$ Although epicardial LV volume calculated in this manner overestimates the true chamber LV volume because it includes myocardial wall volume, a change in epicardial LV volume is an accurate measurement of change in LV chamber volume. ${ }^{28}$

LV systolic performance. Global LV systolic function was quantified by calculating preload recruitable stroke work. External LV stroke work (SW) was calculated as the integral of $\mathrm{LV}$ pressure $(\mathrm{P})$ multiplied by volume $(\mathrm{V})$ over a cardiac cycle for each of several beats at baseline and during caval occlusion as

$$
\mathrm{SW}=\int \mathrm{P} \cdot \mathrm{dV}
$$

Preload recruitable stroke work was the slope of the linear regression of SW on end-diastolic volume (EDV),

$$
\mathrm{SW}=\mathrm{M}_{\mathrm{w}}\left(\mathrm{EDV}-\mathrm{V}_{\mathrm{w}}\right)
$$

where $\mathrm{M}_{\mathrm{w}}$ and $\mathrm{V}_{\mathrm{w}}$ are the slope (preload recruitable stroke work) and volume axis intercept, respectively.

Mitral annular plane, mitral annular size, and leaflet geometry. A mitral annular plane in 3-D space was derived by means of the least-squares estimate regression to place a plane of best fit to the 3-D coordinates of the 8 mitral annular markers. Leaflet geometry was quantified by calculating the perpendicular distances between this mitral annular plane and the leaflet markers (Fig 2). In addition, the 3-D distances between each individual anterior leaflet marker and mid-anterior annular marker No. 1, as well as the distances between each posterior leaflet marker and the 
mid-posterior annular marker No. 5, were computed. The mitral annular size was quantified by measuring the respective distances between the mid-anterior annular marker No. 1 and mid-posterior annular marker No. 5, and between the anterior commissural marker No. 3 and posterior commissural marker No. 7 (Fig 1). These leaflet distances and mitral annular sizes were calculated at 4 consecutive time points during systole: $25 \%, 50 \%$, and $75 \%$ systole, as defined by the relative percentage of LV volume ejected, and at end-systole as defined above. A mean systolic value was derived from the 4 consecutive systolic values.

Statistical analysis. All data are reported as mean \pm 1 SD. The leaflet and annular variables were computed at the 4 consecutive systolic time points, and the average systolic values of the leaflet and annular variables were compared before and during ischemia by the 2-tailed Student $t$ test for paired observations. The mitral annular size of the ring animals was compared with the annular size of the control animals before and during ischemia by means of the 2-tailed independent groups $t$ test with the post hoc Bonferroni inequality correction.

\section{Results}

Postmortem examination revealed that all 8 mitral annular markers were within $1 \mathrm{~mm}$ of the mitral leaflet-left atrial junction in all groups. No ring dehiscence or vegetations were seen in the ring groups. Differences in body weight were not significant among the 3 groups (control $62 \pm 9 \mathrm{~kg}$, Duran $69 \pm 8 \mathrm{~kg}$, and Physio $71 \pm 5 \mathrm{~kg}$ ).

Mitral valve competence. MR was not detected at baseline in the control group; after induction of ischemia, 5 control animals had moderate to severe acute ischemic MR, and 2 had mild to moderate acute ischemic MR. Acute ischemic MR disappeared after deflation of the intracoronary balloon occluders in the control animals. In the ring groups, trace MR was noted in 1 Duran and 1 Physio animal before ischemia, but the severity of MR did not change after circumflex occlusion. The remaining sheep in the ring groups did not have MR either at baseline or during ischemia.

Hemodynamics. The hemodynamic data for all animals in each group before and during ischemia are summarized in Table I. Ischemia caused a decrease in the maximal positive and negative $\mathrm{LV} \mathrm{dP} / \mathrm{dt}$ and endsystolic LV pressure in all 3 groups; preload recruitable stroke work fell in the control and Physio groups, and end-systolic volume and stroke volume were lower during ischemia in the control group.

Anterior mitral leaflet shape. In all control animals, ischemia was accompanied by extension of the anterior mitral leaflet away from the mid-anterior anulus during systole. During ischemia, the anterior mitral leaflet edge marker (No. 12) extended on aver-

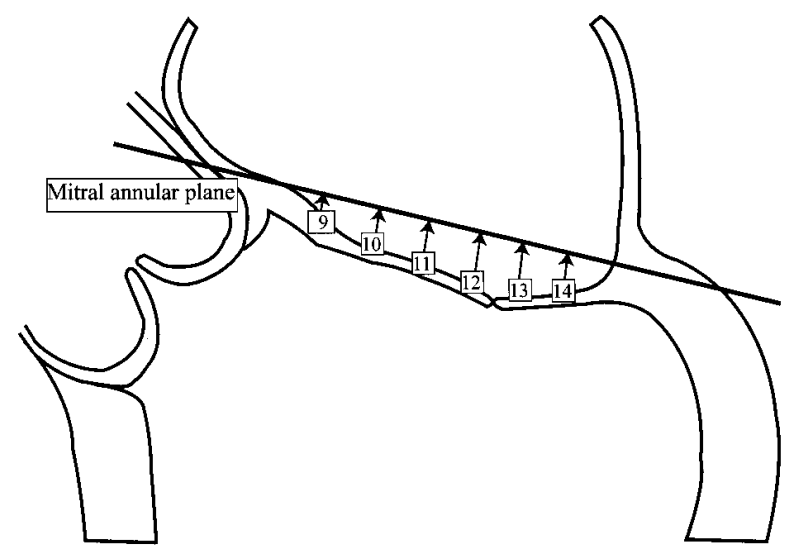

Fig 2. A mitral annular plane (bold line) was located by means of the least-squares estimate regression to fit the annular markers. The perpendicular distances (arrows) between the leaflet markers and the mitral annular plane were measured before and during ischemia.

age $1.0 \pm 0.5 \mathrm{~mm}(P=.01)$ away from the anterior annular marker No. 1 during systole (Table II) toward the center of the valve orifice. The average distance between anterior annular marker No. 1 and anterior mitral leaflet marker No. 11 increased by $0.4 \pm 0.5$ $\mathrm{mm}$ during systole $(P=.04)$. The distances between the other anterior leaflet markers and the mid-anterior anulus did not change significantly during ischemia (Table II). Compared with their nonischemic positions, all anterior leaflet markers were neither displaced toward nor away from the annular plane during ischemia (Table III). In all Duran and Physio animals, anterior leaflet position relative to the mid-anterior anulus and annular plane did not change during ischemia (Tables II and III).

Posterior mitral leaflet shape. In all control animals, LV ischemia was associated with systolic apical tethering (or restricted motion) of the posterior leaflet. During ischemia, the posterior leaflet edge marker No. 13 was displaced apically (away from the annular plane) on average by $0.6 \pm 0.4 \mathrm{~mm}$ during systole $(P=.01)$. During ischemia, the posterior leaflet marker No. 14 was displaced apically by an average of $0.7 \pm$ $0.2 \mathrm{~mm}(P<.001)$ during systole (Table IV). During ischemia, the posterior leaflet did not extend away from the mid-posterior anulus (marker No. 5, Fig 1), and the distances between the posterior leaflet markers and the double-barrel mid-posterior anulus did not change (Table V). In all Duran and Physio animals, the posterior leaflet position with respect to the mid-posterior anulus and mitral annular plane was not altered by ischemia (Tables IV and V). 
Table I. Hemodynamic profile during data acquisition in the preischemic state and during circumflex coronary artery occlusion in all 3 groups

\begin{tabular}{|c|c|c|c|c|c|c|}
\hline & \multicolumn{2}{|c|}{ Control } & \multicolumn{2}{|c|}{ Duran } & \multicolumn{2}{|c|}{ Physio } \\
\hline & Before ischemia & Ischemia & Before ischemia & Ischemia & Before ischemia & Ischemia \\
\hline $\operatorname{HR}\left(\min ^{-1}\right)$ & $107 \pm 11$ & $102 \pm 18$ & $114 \pm 10$ & $96 \pm 32$ & $110 \pm 10$ & $93 \pm 33$ \\
\hline $\mathrm{EDP}(\mathrm{mm} \mathrm{Hg})$ & $18 \pm 6$ & $18 \pm 9$ & $25 \pm 9$ & $26 \pm 7$ & $19 \pm 6$ & $24 \pm 8$ \\
\hline $\mathrm{ESP}(\mathrm{mm} \mathrm{Hg})$ & $111 \pm 19$ & $87 \pm 14 \dagger$ & $102 \pm 13$ & $78 \pm 22 \dagger$ & $101 \pm 14$ & $70 \pm 14^{*}$ \\
\hline EDV (mL) & $144 \pm 32$ & $148 \pm 37$ & $198 \pm 43$ & $197 \pm 43$ & $177 \pm 47$ & $179 \pm 46$ \\
\hline ESV (mL) & $115 \pm 23$ & $125 \pm 26^{*}$ & $159 \pm 27$ & $165 \pm 32$ & $140 \pm 44$ & $147 \pm 44$ \\
\hline $\mathrm{SV}(\mathrm{mL})$ & $30 \pm 10$ & $23 \pm 11 \dagger$ & $39 \pm 18$ & $33 \pm 13$ & $37 \pm 6$ & $31 \pm 10$ \\
\hline$+\mathrm{dP} / \mathrm{dt}_{\max }(\mathrm{mm} \mathrm{Hg} / \mathrm{s})$ & $2001 \pm 349$ & $1631 \pm 317 *$ & $1537 \pm 336$ & $1126 \pm 351 \dagger$ & $1762 \pm 372$ & $1281 \pm 202^{*}$ \\
\hline$-\mathrm{dP} \mathrm{dt}_{\max }(\mathrm{mm} \mathrm{Hg} / \mathrm{s})$ & $1965 \pm 397$ & $1513 \pm 386^{*}$ & $1536 \pm 292$ & $1069 \pm 437 \dagger$ & $1742 \pm 285$ & $1109 \pm 222^{*}$ \\
\hline PRSW (mm Hg) & $74 \pm 13$ & $57 \pm 15 \dagger$ & $55 \pm 13$ & $41 \pm 15$ & $69 \pm 19$ & $40 \pm 15 \dagger$ \\
\hline
\end{tabular}

Data are expressed as mean $\pm 1 \mathrm{SD}$. Differences between the preischemic and ischemic measurements were significant at $* P<.01$ and $\dagger P<.05$. $H R$, Heart rate; $E D P$, end-diastolic pressure; $E S P$, end-systolic pressure; $E D V$, end-diastolic volume; $E S V$, end-systolic volume; $S V$, stroke volume; $+d P / d t_{\text {max }}$, maximal value of positive $L V$ $\mathrm{dP} / \mathrm{dt} ;-d P / d t_{\max }$, maximal value of negative $\mathrm{LV} \mathrm{dP/dt;} P R S W$, preload recruitable stroke work.

Table II. Average distances between anterior mitral leaflet markers and the mid-anterior anulus during systole

\begin{tabular}{|c|c|c|c|}
\hline & Control $_{\text {average }}(\mathrm{mm})$ & $\operatorname{Duran}_{\text {average }}(\mathrm{mm})$ & Physio $_{\text {average }}(\mathrm{mm})$ \\
\hline \multicolumn{4}{|l|}{ Marker 9} \\
\hline Before ischemia & $5.9 \pm 1.8$ & $5.9 \pm 1.0$ & $4.8 \pm 0.8$ \\
\hline Ischemia & $5.9 \pm 1.9$ & $5.9 \pm 1.1$ & $5.0 \pm 1.1$ \\
\hline Difference & $0.0 \pm 0.2$ & $0.0 \pm 0.6$ & $0.2 \pm 0.3$ \\
\hline$P$ value & NS & NS & NS \\
\hline \multicolumn{4}{|l|}{ Marker 10} \\
\hline Before ischemia & $10.3 \pm 2.5$ & $10.5 \pm 0.8$ & $8.9 \pm 1.5$ \\
\hline Ischemia & $10.5 \pm 2.4$ & $10.6 \pm 0.7$ & $9.0 \pm 1.6$ \\
\hline Difference & $0.2 \pm 0.5$ & $0.1 \pm 0.2$ & $0.1 \pm 0.1$ \\
\hline$P$ value & NS & NS & NS \\
\hline \multicolumn{4}{|l|}{ Marker 11} \\
\hline Before ischemia & $16.0 \pm 2.8$ & $14.9 \pm 1.8$ & $13.8 \pm 1.2$ \\
\hline Ischemia & $16.4 \pm 2.9 \dagger$ & $14.9 \pm 1.7$ & $13.9 \pm 1.4$ \\
\hline Difference & $0.4 \pm 0.5$ & $0.0 \pm 0.2$ & $0.0 \pm 0.1$ \\
\hline$P$ value & .04 & NS & NS \\
\hline \multicolumn{4}{|l|}{ Marker 12} \\
\hline Before ischemia & $18.7 \pm 1.2$ & $19.7 \pm 1.9$ & $18.6 \pm 1.9$ \\
\hline Ischemia & $19.7 \pm 1.4 \dagger$ & $19.7 \pm 2.1$ & $18.8 \pm 2.3$ \\
\hline Difference & $1.0 \pm 0.5$ & $0.0 \pm 0.3$ & $0.1 \pm 0.3$ \\
\hline$P$ value & .01 & NS & NS \\
\hline
\end{tabular}

Data are expressed as mean \pm SD. Difference denotes the difference between the average preischemic and ischemic distances, which were significant at $† P<.05$. NS, Not significant.

Mitral annular size. During ischemia, the mid-anterior to mid-posterior and commissural to commissural mitral annular size increased significantly during systole in all control animals (Table VI). In all Duran and Physio animals, mitral annular size was not altered by ischemia (Table VI). Mitral annular size in Duran and Physio animals was significantly smaller than in the control animals before and during ischemia $(P<.001$, Table VI).

\section{Discussion}

Perturbations of leaflet geometry are widely accepted to be the common final end point through which LV ischemia - by altering the spatial relationships of subvalvular structures-causes incomplete mitral leaflet closure and resultant acute ischemic MR. The perturbations of leaflet shape associated with acute ischemic MR, however, have not been clarified. Hence, confusion about the changes of leaflet shape has obfuscated 
Table III. Average perpendicular distances between the anterior mitral leaflet markers and mitral annular plane during systole

\begin{tabular}{lccc}
\hline & Control $_{\text {average }}(\mathrm{mm})$ & Duran $_{\text {average }}(\mathrm{mm})$ & Physio $_{\text {average }}(\mathrm{mm})$ \\
\hline Marker 9 & & & $-0.3 \pm 0.5$ \\
$\quad$ Before ischemia & $-0.3 \pm 0.8$ & $0.2 \pm 0.6$ & $-0.6 \pm 0.8$ \\
Ischemia & $-0.3 \pm 0.8$ & $-0.1 \pm 0.8$ & $-0.3 \pm 0.4$ \\
Difference & $0.0 \pm 0.6$ & $-0.2 \pm 0.6$ & .16 \\
$P$ value & $\mathrm{NS}$ & $\mathrm{NS}$ & $-2.3 \pm 0.5$ \\
Marker 10 & & & $-2.6 \pm 0.8$ \\
$\quad$ Before ischemia & $-3.3 \pm 1.0$ & $-2.1 \pm 1.0$ & $-0.3 \pm 0.3$ \\
Ischemia & $-3.5 \pm 1.1$ & $-2.3 \pm 1.1$ & .11 \\
Difference & $-0.1 \pm 0.2$ & $-0.1 \pm 0.3$ & $-3.9 \pm 0.8$ \\
$P$ value & .08 & .08 & $-4.0 \pm 1.0$ \\
Marker 11 & & $-4.0 \pm 1.2$ & $-0.1 \pm 0.5$ \\
Before ischemia & $-6.5 \pm 1.7$ & $-4.0 \pm 1.3$ & $\mathrm{NS}$ \\
Ischemia & $-6.5 \pm 1.8$ & $0.0 \pm 0.1$ & $\mathrm{NS}$ \\
Difference & $0.1 \pm 0.2$ & & $-5.3 \pm 2.5$ \\
$P$ value & $\mathrm{NS}$ & $-6.0 \pm 2.1$ & $-5.5 \pm 2.5$ \\
Marker 12 & $-8.2 \pm 1.5$ & $-5.8 \pm 2.4$ & $-0.2 \pm 0.7$ \\
Before ischemia & $-8.0 \pm 1.2$ & $0.2 \pm 0.3$ & $\mathrm{NS}$ \\
Ischemia & $0.1 \pm 0.5$ & $\mathrm{NS}$ & \\
Difference & $\mathrm{NS}$ & & \\
$P$ value & & &
\end{tabular}

Data are expressed as mean \pm SD with positive values indicating marker position cephalad to the annular plane and negative values indicating marker position caudal to the annular plane. Difference denotes the change between the average preischemic and the ischemic distances. Differences with a positive sign represent displacement toward the annular plane and those with a negative sign indicate apical displacement away from the annular plane. NS, Not significant.

Table IV. Average perpendicular distances between the posterior mitral leaflet markers and mitral annular plane during systole

\begin{tabular}{lccc}
\hline & Control $_{\text {average }}(\mathrm{mm})$ & Duran $_{\text {average }}(\mathrm{mm})$ & Physio $_{\text {average }}(\mathrm{mm})$ \\
\hline Marker 13 & & & $-8.2 \pm 0.7$ \\
$\quad$ Before ischemia & $-7.9 \pm 1.8$ & $-7.8 \pm 1.8$ & $-8.2 \pm 0.8$ \\
Ischemia & $-8.5 \pm 1.9 \dagger$ & $-7.6 \pm 2.3$ & $0.0 \pm 0.3$ \\
Difference & $-0.6 \pm 0.4$ & $0.3 \pm 0.8$ & $\mathrm{NS}$ \\
$P$ value & .01 & $\mathrm{NS}$ & $-3.0 \pm 1.4$ \\
Marker 14 & $-4.2 \pm 1.7$ & $-3.4 \pm 2.1$ & $-3.1 \pm 1.3$ \\
$\quad$ Before ischemia & $-4.9 \pm 1.7^{*}$ & $-3.8 \pm 2.0$ & $-0.1 \pm 0.4$ \\
Ischemia & $-0.7 \pm 0.2$ & $-0.4 \pm 0.4$ & $\mathrm{NS}$ \\
$\quad$ Difference & $<.001$ & .07 & \\
$P$ value & & & \\
\hline
\end{tabular}

Data are expressed as mean \pm SD with positive values indicating marker position cephalad to the annular plane and negative values indicating marker position caudal to the annular plane. Difference denotes the change between the average preischemic and ischemic distances. Differences with a positive sign represent displacement toward the annular plane and those with a negative sign indicate apical displacement away from the annular plane $(* P<.01$ and $\dagger P<.05) . N S$, Not significant.

our understanding of the underlying mechanism(s) responsible for acute ischemic MR. For instance, Gorman and associates ${ }^{29}$ showed that the posterior papillary muscle tip moved $1.4 \pm 0.6 \mathrm{~mm}$ closer to the centroid of the mitral anulus with ischemia and that the anterior papillary tip moved $0.9 \pm 0.7 \mathrm{~mm}$ away from the centroid of the mitral anulus at end-systole in an ovine model. Thus, they inferred that the nature and direction of these papillary tip displacements would alter the leaflet tethering distance and result in relative prolapse of the posterior leaflet and restriction of the anterior leaflet. The echocardiographic description of acute ischemic MR published by Godley and cowork$\mathrm{ers}^{1}$ does lend clinical support to their stance, in that the motion of the anterior mitral leaflet was often observed to be restricted during systolic closure in association with relative prolapse of the posterior leaflet. Posterior leaflet prolapse was also observed in the experimental canine model of LV ischemia described by Tei and coworkers. ${ }^{6}$ However, Godley and associates ${ }^{1}$ also 
Table V. Average distances between posterior mitral leaflet markers and the mid-posterior anulus during systole

\begin{tabular}{|c|c|c|c|}
\hline & Control $_{\text {average }}(\mathrm{mm})$ & Duran $_{\text {average }}(\mathrm{mm})$ & Physio $_{\text {average }}(\mathrm{mm})$ \\
\hline \multicolumn{4}{|l|}{ Marker 13} \\
\hline Before ischemia & $12.2 \pm 1.5$ & $9.1 \pm 1.4$ & $9.2 \pm 1.1$ \\
\hline Ischemia & $12.6 \pm 1.7$ & $8.6 \pm 2.0$ & $9.3 \pm 1.3$ \\
\hline Difference & $0.4 \pm 0.4$ & $-0.5 \pm 0.9$ & $0.1 \pm 0.3$ \\
\hline$P$ value & .08 & NS & NS \\
\hline \multicolumn{4}{|l|}{ Marker 14} \\
\hline Before ischemia & $7.2 \pm 2.5$ & $5.0 \pm 1.7$ & $4.4 \pm 0.7$ \\
\hline Ischemia & $7.4 \pm 2.5$ & $5.2 \pm 1.8$ & $4.5 \pm 0.8$ \\
\hline Difference & $0.2 \pm 0.4$ & $0.1 \pm 0.4$ & $0.1 \pm 0.2$ \\
\hline$P$ value & .19 & NS & NS \\
\hline
\end{tabular}

Data are expressed as mean \pm SD. Difference denotes the difference between the average preischemic and ischemic distances. NS, Not significant.

Table VI. Average mitral annular size during systole

\begin{tabular}{|c|c|c|c|}
\hline Axes & Control $_{\text {average }}(\mathrm{mm})$ & Duran $_{\text {average }}(\mathrm{mm}) \neq$ & Physio $_{\text {average }}(\mathrm{mm}) \neq$ \\
\hline \multicolumn{4}{|c|}{ Mid-anterior to mid-posterior mitral anulus } \\
\hline Before ischemia & $25.7 \pm 0.9$ & $22.0 \pm 2.3$ & $21.6 \pm 1.3$ \\
\hline Ischemia & $28.1 \pm 1.6 \dagger$ & $22.2 \pm 2.3$ & $21.6 \pm 1.4$ \\
\hline Difference & $2.3 \pm 1.6$ & $0.2 \pm 0.3$ & $0 \pm 0.2$ \\
\hline$P$ value & .008 & NS & NS \\
\hline \multicolumn{4}{|c|}{ Commissure to commissure } \\
\hline Before ischemia & $34.4 \pm 1.5$ & $28.4 \pm 1.6$ & $29.2 \pm 3.5$ \\
\hline Ischemia & $35.3 \pm 1.9^{*}$ & $28.4 \pm 1.6$ & $29.3 \pm 3.6$ \\
\hline Difference & $0.8 \pm 0.7$ & $0 \pm 0.6$ & $0.1 \pm 0.1$ \\
\hline$P$ value & .02 & NS & .08 \\
\hline
\end{tabular}

Data expressed as mean \pm SD. Difference denotes the differences between the average preischemic and ischemic mitral annular size $(* P<.01$ and $\dagger P<.05)$. NS, Not significant.

¥The average mitral annular size in the Duran and Physio animals, as measured in the 2 axes, was significantly smaller than the control animals before and during ischemia $(P<.001)$ using the independent groups $t$ test with the Bonferroni inequality correction.

observed posterior leaflet restriction in $18 \%$ of patients with acute ischemic MR, and Tei and colleagues ${ }^{6}$ also reported anterior mitral leaflet prolapse.

The description of a leaflet-tethering hypothesis published by Otsuji and colleagues ${ }^{8,10,11}$ seems to be a more plausible mechanism for the genesis of acute ischemic MR. This group reported increased tethering distance of the papillary muscles from the mid-anterior anulus during acute posterior LV ischemia - which has also been shown independently by our group ${ }^{30}$ in an analysis of papillary muscle geometry-and greater tethering distance correlated with increased severity of MR. They did not, however, localize the site of leaflet restriction. Furthermore, in their canine model of global LV dysfunction, ${ }^{8}$ the increased tethering distance of the papillary muscles from the anterior anulus was accompanied by restriction of both mitral leaflets during systole.

Our earlier efforts focused on leaflet geometry in another (canine) animal model demonstrated that the anterior commissure portion of the posterior leaflet, that is, opposite to the ischemic LV region, was restrict- ed by $0.8 \mathrm{~mm}$ throughout systole and that the posterior commissure part of the anterior leaflet rotated toward the posterior anulus away from the anterior anulus. ${ }^{31}$ Our subsequent experiments in an ovine model of acute LV ischemia reported sluggish motion of both mitral leaflets in very early systole with delayed mitral leaflet closure, which we termed "leaflet loitering." ${ }^{24}$ No leaflet restriction in mid to late systole was observed in this ovine experiment, and this inconsistency compared with the canine findings was probably due to the different internal coordinate systems used, wherein different mitral annular landmarks were chosen as a frame of reference to analyze leaflet motion and the ventricular apex was the only landmark common to both experiments. In addition, gross movements of the LV apex can obscure subtle deformations of leaflet shape when observed in an internal coordinate system anchored to the apex. To avoid the possible limitations of such a coordinate system, in the present study we located a best-fit plane of the mitral anulus using least-squares estimate regression and measured perpendicular distances from the annular plane to quantify changes in 
leaflet geometry. This stable annular frame of reference is unlike the prior internal coordinate systems used in that it is not directly dependent on LV apical position.

The findings of leaflet restriction along the midline of the posterior leaflet and the unchanged position of the midline of the anterior leaflet with respect to the annular plane throughout systole in this current study conflict with other experimental ${ }^{6,8,29}$ and clinical observations. ${ }^{1,2,4,5}$ Demonstration of midline posterior leaflet restriction is in keeping with Carpentier's notion of ischemic MR (type IIIb restricted systolic leaflet motion [personal communication]) and lends support to the leaflet-tethering hypothesis put forward by Otsuji and colleagues as a mechanism for the genesis of ischemic MR. The magnitude of displacement of the posterior leaflet was very small $(<1 \mathrm{~mm})$, and this small difference in leaflet shape reinforces the concept advocated by Gorman and associates ${ }^{32}$ that multiple, very small (submillimeter) perturbations of the 3-D spatial locations of the subvalvular structures are instrumental in the genesis of acute ischemic MR. The finding of Carpentier type IIIb restricted leaflet motion involving solely the posterior leaflet with sparing of the anterior leaflet, however, runs contrary to the thinking of other proponents. They believe that global LV systolic dysfunction is the main mechanism responsible for incomplete mitral leaflet closure. As lower LV pressure results in less force generation on the leaflets during closure, global LV systolic dysfunction would be expected to cause a similar degree of restricted leaflet motion affecting both the anterior and posterior mitral leaflets. ${ }^{9}$

Analysis of distances from the mid-anterior anulus revealed that the shape along the midline of the anterior leaflet changed during ischemia as the anterior leaflet edge marker and the marker adjacent to it extended away from the mid-anterior anulus by $1.0 \mathrm{~mm}$ and $0.4 \mathrm{~mm}$, respectively, during systole. Extension of the anterior leaflet in this direction remains consistent with the leaflet-tethering hypothesis; it is not inconceivable that a greater tethering distance from the posterior papillary tip (as might be seen with a larger acute ischemic insult or with chronic LV ischemia/infarction) would exert traction on the anterior mitral leaflet, thereby dragging the leaflet edge away from the anterior anulus during ischemia. These findings have been corroborated recently in an in vitro preparation by Nielsen and associates, ${ }^{33}$ who were examining the impact of papillary muscle malalignment on leaflet geometry; this group demonstrated that posterolateral displacement of the posterior papillary muscle was accompanied by extension of the anterior mitral leaflet with an increase in anterior leaflet surface area and restriction of posterior leaflet motion. They also described changes in leaflet geometry in other portions of the leaflet near the commissures, which was not addressed in our study. The interactions among leaflet, annular, and subvalvular 3-D geometry are complex; further studies are underway in our laboratory to integrate all these changes in leaflet, annular, and subvalvular dynamic 3-D geometry during ischemia.

The salutary effects of annuloplasty rings in preventing acute ischemic MR during acute LV ischemia have been previously reported by our group using these same animals. We demonstrated that annuloplasty rings prevented early systolic loitering of the mitral leaflets and achieved timely and competent valve closure. ${ }^{25}$ Detailed leaflet geometry, however, was not the focus of this earlier work. In the present study, annuloplasty rings appeared to ameliorate the adverse changes in 3D leaflet geometry associated with acute ischemic MR during acute LV ischemia in sheep, namely, anterior leaflet extension and posterior leaflet restriction. Thus, at least in theory, annuloplasty rings might be just as effective in treating patients with acute ischemic MR due to Carpentier type IIIb restricted leaflet restriction as they are in treating those with acute ischemic MR due to simple annular dilatation and Carpentier type I (normal) leaflet motion. ${ }^{34}$ On the other hand, if the extent of apical tethering of the posterior leaflet is great enough, this may not be the case no matter how small the ring makes the mitral anulus. The exact mechanisms by which an annuloplasty ring corrects acute ischemic MR, however, are not known; they may possibly be related to restoration of more favorable subvalvular 3-D dynamic geometry than reduction of annular size, as the annular and subvalvular ventricular dynamics are tightly coupled. ${ }^{30,35}$ Alternatively, it may be that the annuloplasty rings convert a normal bileaflet mitral valve into a functionally unileaflet valve by restricting posterior leaflet motion, ${ }^{36}$ with the resultant monoleaflet mitral valve somehow rendered less vulnerable to submillimeter perturbations of the subvalvular apparatus during ischemia. Additionally, annuloplasty rings - by reducing annular size-may increase leaflet coaptation area to such a degree that there is sufficient reserve in the system to deal with the impact of the small spatial perturbations associated with acute LV ischemia.

Our findings of subtle leaflet deformations during acute ischemia raise the question as to how surgical repair methods can accurately correct spatial perturbations of such small magnitude. The frustratingly rather unpredictable results of various surgical repair tech- 
niques in patients with acute ischemic MR may be due to the difficulty inherent in surgically restoring these submillimeter perturbations of the mitral subvalvular complex necessary for competent valve closure. Nevertheless, the present study showed that annuloplasty rings that reduced mitral annular size prevented acute ischemic MR in an ovine model of LV ischemia. Finally, annuloplasty rings primarily address only the annular abnormalities induced by ischemic heart disease and do not directly remedy any perturbations in the subvalvular apparatus or leaflet apical tethering.

\section{Limitations}

In this experimental preparation, the annuloplasty ring was implanted prophylactically before the ischemic insult. Obviously, preemptive treatment is not analogous to the clinical situation whereby ischemia and infarction with consequent valve regurgitation precede surgical treatment. These findings can only be interpreted in the setting of acute ischemia in normal sheep hearts and cannot be directly extrapolated to chronic ischemic MR in the clinical scenario where LV dilatation and remodeling take place. Further, the exact timing of the MR could not be determined during systole; it is uncertain whether the period of leaflet shape deformation was necessarily accompanied by valve leakage at the time when the leaflet measurements were made. The markers were placed only along the middle of each leaflet; therefore, we have no data to address leaflet motion and coaptation toward the commissures. We are planning future experiments with a denser and larger leaflet marker array to concentrate on this question. The myocardial marker method provides reproducible determination of 3-D marker position with submillimeter spatial resolution every $16.7 \mathrm{~ms}$, but requires suturing small metal markers to the leaflets. It is unlikely that the markers interfered with mitral leaflet motion because they are very small (aggregate mass $=20 \pm 6 \mathrm{mg}$ ). (Even when we grossly overloaded the anterior leaflet with a larger number of heavy markers [total mass $=184 \mathrm{mg}$ ] in other sheep hearts, the peak anterior leaflet opening velocity by epicardial pulsed wave Doppler echocardiography was $0.47 \pm 0.5$ $\mathrm{m} / \mathrm{s}$ compared with $0.45 \pm 0.06 \mathrm{~m} / \mathrm{s}$ for leaflets without any markers implanted.) This study does not address the differences in leaflet geometry that may be observed with varying degrees of ischemia as exemplified by distal versus proximal circumflex occlusion and brief versus prolonged intracoronary balloon occlusion. There are also limitations inherent in using a coordinate system based on a plane fitted to a nonplanar mitral anulus. Studies are presently underway in the laborato- ry to evaluate the stability of the annular plane as a frame of reference. Finally, a major limitation of this work is the acute preparation we used; a chronic animal model is required to address the more important question of chronic infarction with its attendant ischemic MR, LV remodeling, and chronic LV volume overload.

We appreciate the technical assistance provided by Mary K. Zasio, BA, Carol W. Mead, BA, and Erin M. Schultz, BS.

\section{REFERENCES}

1. Godley RW, Wann LS, Rogers EW, Feigenbaum H, Weyman AE. Incomplete mitral leaflet closure in patients with papillary muscle dysfunction. Circulation 1981;63:565-71.

2. Kaul S, Pearlman JD, Touchstone DA, Esquival L. Prevalence and mechanisms of mitral regurgitation in the absence of intrinsic abnormalities of the mitral leaflets. Am Heart J 1989;118:96372.

3. Ogawa S, Hubbard FE, Mardelli TJ, Dreifus LS. Cross-sectional echocardiographic spectrum of papillary muscle dysfunction. Am Heart J 1979;97:312-21.

4. Izumi S, Miyatake K, Beppu S, Park YD, Nagata S, Kinoshita N, et al. Mechanism of mitral regurgitation in patients with myocardial infarction: a study using real-time two-dimensional Doppler flow imaging and echocardiography. Circulation 1987;76:77785.

5. Kinney EL, Frangi MJ. Value of two-dimensional echocardiographic detection of incomplete mitral leaflet closure. Am Heart J 1985;109;87-90.

6. Tei C, Sakamaki T, Shah PM, Meerbaum S, Kondo S, Shimoura $\mathrm{K}$, et al. Mitral valve prolapse in short-term experimental coronary occlusion: a possible mechanism of ischemic mitral regurgitation. Circulation 1983;68:183-9.

7. Kono T, Sabbah HN, Stein PD, Brymer JF, Khaja F. Left ventricular shape as a determinant of functional mitral regurgitation in patients with severe heart failure secondary to either coronary artery disease or idiopathic dilated cardiomyopathy. Am J Cardiol 1991;68:355-9.

8. Otsuji Y, Handschumacher MD, Schwammenthal E, Jiang L, Song JK, Guerrero JL, et al. Insights from three-dimensional echocardiography into the mechanism of functional mitral regurgitation: direct in vivo demonstration of altered leaflet tethering geometry. Circulation 1997;96:1999-2008.

9. Kaul S, Spotnitz WD, Glasheen WP, Touchstone DA. Mechanism of ischemic mitral regurgitation: an experimental evaluation. Circulation 1991;84:2167-80.

10. Otsuji Y, Nathan N, Handschumacher MD, Coulter S, Liel-Cohen $\mathrm{N}$, D'Ambra M, et al. Mechanism of ischemic mitral regurgitation: intraoperative evaluation of leaflet tethering geometry by three-dimensional geometry (abstract). Circulation 1997;96 (Suppl):I-156.

11. Otsuji Y, Handschumacher MD, Liel-Cohen N, Tanabe H, Jiang $\mathrm{L}$, Schwammenthal E, et al. Mechanism of functional ischemic mitral regurgitation: in vivo validation of the leaflet tethering hypothesis by three-dimensional echocardiography (abstract). Circulation 1997;96(Suppl):I-32.

12. Kono T, Sabbah HN, Rosman H, Alam M, Jafri S, Stein PD, et al. Mechanism of functional mitral regurgitation during acute myocardial ischemia. J Am Coll Cardiol 1992;19:1101-5. 
13. Kono T, Sabbah HN, Rosman H, Alam M, Jafri S, Goldstein S. Left ventricular shape is the primary determinant of functional mitral regurgitation in heart failure. $\mathrm{J}$ Am Coll Cardiol 1992;20:1594-8.

14. Akins CW, Hilgenberg AD, Buckley MJ, Vlahakes GJ, Torchiana DF, Daggett WM, et al. Mitral valve reconstruction versus replacement for degenerative or ischemic mitral regurgitation. Ann Thorac Surg 1994;58:668-75.

15. David TE. Techniques and results of mitral valve repair for ischemic mitral regurgitation. J Card Surg 1994;9(Suppl II):274-7.

16. Hendren WG, Nemec JJ, Lytle BW, Loop FD, Taylor PC, Stewart $\mathrm{RW}$, et al. Mitral valve repair for ischemic mitral insufficiency. Ann Thorac Surg 1991;52:1246-51.

17. Czer LS, Maurer G, Trento A, DeRobertis M, Nessim S, Blanche $\mathrm{C}$, et al. Comparative efficacy of ring and suture annuloplasty for ischemic mitral regurgitation. Circulation 1992;86 (Suppl):II-4652.

18. Hausmann H, Siniawski H, Hetzer R. Mitral valve reconstruction and replacement for ischemic mitral insufficiency: seven years' follow up. J Heart Valve Dis 1999;8:536-42.

19. Cohn LH, Rizzo RJ, Adams DH, Couper GS, Sullivan TE, Collins JJ Jr, et al. The effect of pathophysiology on the surgical treatment of ischemic mitral regurgitation: operative and late risks of repair versus replacement. Eur J Cardiothorac Surg 1995;9:568-74.

20. Wiernup PN, Gillinov AM, Blackstone EH, Cosgrove DM, Bishay ES, McCarthy PM. Repair is preferable to replacement for ischemic mitral regurgitation (abstract). Eightieth Annual Meeting of The American Association for Thoracic Surgery, Toronto, Ontario, Canada; 2000, p. 122.

21. Liel-Cohen J, Otsuji Y, Vlahakes GJ, Akins CW, Levine RA. Functional ischemic mitral regurgitation can persist despite ring annuloplasty: mechanistic insights (abstract). Circulation 1997;96(Suppl):I-540.

22. von Oppell UO, Stemmet F, Brink J, Commerford PJ, Heijke SA. Ischemic mitral valve repair surgery. J Heart Valve Dis 2000;9:64-73.

23. Oury JH, Cleveland JC, Duran CG, Angell WW. Ischemic mitral valve disease: classification and systemic approach to management. J Card Surg 1994;9(Suppl):262-73.

24. Glasson JR, Komeda M, Daughters GT, Bolger AF, Karlsson MO, Foppiano LE, et al. Early systolic mitral leaflet "loitering" during acute ischemic mitral regurgitation. J Thorac Cardiovasc Surg 1998;116:193-205.

25. Timek T, Glasson JR, Dagum P, Green GR, Nistal JF, Komeda M, et al. Ring annuloplasty prevents delayed leaflet coaptation and mitral regurgitation during acute left ventricular ischemia. J Thorac Cardiovasc Surg 2000;119:774-83.

26. Glasson JR, Komeda MK, Daughters GT, Niczyporuk MA, Bolger AF, Ingels NB, et al. Three-dimensional regional dynamics of the normal mitral anulus during left ventricular ejection. J Thorac Cardiovasc Surg 1996;111:574-85.

27. Niczyporuk MA, Miller DC. Automatic tracking and digitization of multiple radiopaque myocardial markers. Comput Biomed Res 1991;24:129-42.

28. Moon MR, DeAnda A Jr, Daughters GT 2nd, Ingels NB Jr, Miller DC. Experimental evaluation of different chordal preservation methods during mitral valve replacement. Ann Thorac Surg 1994;58:931-43.

29. Gorman JH 3rd, Jackson BM, Gorman RC, Kelley ST, Gikakis N, Edmunds LH Jr. Papillary muscle discoordination rather than increased annular area facilitates mitral regurgitation after acute posterior myocardial infarction. Circulation 1997;96(Suppl):II124-7.

30. Dagum P, Timek TA, Green GR, Lai DT, Daughters GT, Liang $\mathrm{DH}$, et al. A coordinate-free analysis of mitral valve dynamics in normal and ischemic hearts. Circulation. In press.

31. Komeda M, Glasson JR, Bolger AF, Daughters GT 2nd, MacIssac A, Oesterle SN, et al. Geometric determinants of ischemic mitral regurgitation. Circulation 1997;96(Suppl):II128-33.

32. Gorman JH 3rd, Gorman RC, Jackson BM, Hiramatsu Y, Gikakis $\mathrm{N}$, Kelley ST, et al. Distortions of the mitral valve in acute ischemic mitral regurgitation. Ann Thorac Surg 1997;64:1026-31.

33. Nielsen SL, Nygaard H, Fontaine AA, Hasenkam JM, He S, Yoganathan AP. Papillary muscle misalignment causes multiple mitral regurgitant jets: an ambiguous mechanism for functional mitral regurgitation. J Heart Valve Dis 1999;8:551-64.

34. Dion R, Benetis R, Elias B, Guennaoui T, Raphael D, Van Dyck $\mathrm{M}$, et al. Mitral valve procedures in ischemic regurgitation. J Heart Valve Dis 1995;4(Suppl II):S124-9.

35. Dagum P, Green GR, Glasson JR, Daughters GT, Bolger AF, Foppiano LE, et al. Potential mechanism of left ventricular outflow tract obstruction after mitral ring annuloplasty. J Thorac Cardiovasc Surg 1999;117:472-80.

36. Green GR, Dagum P, Glasson JR, Nistal JF, Daughters GT 2nd, Ingels NB Jr, et al. Restricted posterior leaflet motion after mitral ring annuloplasty. Ann Thorac Surg 1999;68:2100-6.

\section{Discussion}

Dr Alain F. Carpentier (Paris, France). This presentation confirms what we have said for years, that remodeling annuloplasty permits restoration of the coaptation between the 2 leaflets. I have only one question. Did you downsize the ring to facilitate the coaptation, or did you size the ring according to the classic measurement of the anterior leaflet?

Dr Lai. Thank you, Dr Carpentier. The rings were not undersized. We used standard methods based on the intertrigonal distance and anterior leaflet area to determine the size of the annuloplasty ring. The average ring size was between 28 and $31 \mathrm{~mm}$. This study showed that rings sized by standard methods can prevent acute ischemic MR in a previously normal LV in an ovine model. However, further studies are needed to address the question as to whether these rings would be effective in treating chronic ischemic MR. 